\title{
Ocena twardości warstw nawęglanych i hartowanych indukcyjnie na stali AMS 6414 z zastosowaniem magnetycznych technik nieniszczących
}

\author{
Evaluation of hardness layers carburizing \\ or induction hardened the steel AMS 6414 \\ using magnetic non-destructive techniques
}

\section{Streszczenie}

Praca dotyczy oceny możliwości identyfikacji zmian twardości warstw nawęglanych i hartowanych indukcyjnie, z wykorzystaniem nieniszczących technik magnetycznych. Badania przeprowadzono na zestawie trzech próbek, ze stali AMS 6414, poddanych procesowi nawęglania, w atmosferze o różnym stężeniu węgla, a następnie hartowaniu oraz na próbce bez warstwy. Próbki z warstwami o różnej twardości (i stałej grubości - 1,2 mm) poddano badaniom technikami nieniszczącymi, z zastosowaniem prądów wirowych i analizy szumów Barkhausena. Badania metodą prądów wirowych polegały na ocenie zmian kąta fazowego uzyskanego w efekcie oddalenia od warstw o różnej twardości. Jednocześnie poddano analizie obwiednie sygnału Efektu Barkhausena, Wyniki tych badań pozwoliły zidentyfikować różnice $w$ twardości próbek ze stali, z warstwą o różnym stężeniu węgla.

W celu weryfikacji pomiarów metodami nieniszczącymi wykonano jakościowe i ilościowe badania mikroskopowe oraz rozkłady mikrotwardości na przekrojach próbek.

Słowa kluczowe: nawęglanie; warstwy hartowane indykacyjnie; szumy Barkhausena; prądy wirowe; profile mikrotwardości

\begin{abstract}
The work concerns the evaluation of the possibility of identifying changes in hardness of carburizing and induction hardened layer, using magnetic non-destructive techniques. The research was conducted on a set of three samples, AMS 6414 steel subjected to carburizing process in an atmosphere containing varying concentrations of carbon, and then quenched and the sample without the layer. Samples with the layers of different hardness (of constant thickness $-1.2 \mathrm{~mm}$ ) was subjected to non-destructive testing techniques, using eddy currents and analysis of Barkhausen noise. Eddy current testing method consisted of evaluating changes in the phase angle obtained as a result of separation from layers of different hardness. At the same time analyzed the envelope signal Barkhausen Effect, results of these studies have identified differences in the hardness of samples of steel with a layer of varying concentrations of carbon. In order to verify the measurements made by non-destructive methods qualitative and quantitative microscopy and microhardness distributions on cross sections samples.
\end{abstract}

Keywords: carburizing; induction-hardened layer; Barkhausen noise; eddy currents; micro-hardness profiles

\section{Wstęp}

W produkcji podzespołów silników lotniczych wszystkie elementy poddawane są kontroli jakości. W przypadku elementów hartowanych indukcyjnie jednym z kontrolowanych parametrów jest twardość i grubość utwardzonej warstwy. Wyznaczenie tych danych wymaga wykonania badań na zgładach metalograficznych, czyli zniszczenia części obrabianych detali, co zwiększa koszt produkcji. Możliwość wykorzystania nieniszczących technik badawczych do ilościowej oceny wymaganych parametrów, np. w oparciu o metody magnetyczne, pozwoli na zwiększenie efektywności procedur diagnostycznych i ograniczy starty produkcyjne.

\section{Materiał i metodyka}

Badania prowadzono na zestawie czterech próbek walcowych, ze stali AMS 6414, o geometrii umożliwiającej wykonanie pomiarów technikami nieniszczącymi, poddanych

Dr inż. Dominik Kukla - Instytut Podstawowych Problemów Techniki PAN, dr inż. Leszek Piotrowski - Politechnika Gdańska, mgr inż. Maciej Szwed - Politechnika Warszawska.

Autor korespondencyjny/Corresponding author. dkukla@ippt.gov.pl 
procesowi nawęglania, $\mathrm{w}$ atmosferze o różnym stężeniu węgla, a następnie hartowaniu indukcyjnemu. Pozwoliło to uzyskać warstwy o różnych twardościach, przy stałej grubości (1,2 mm), zgodnie z opracowanym modelem przedstawionym na rysunku 1.

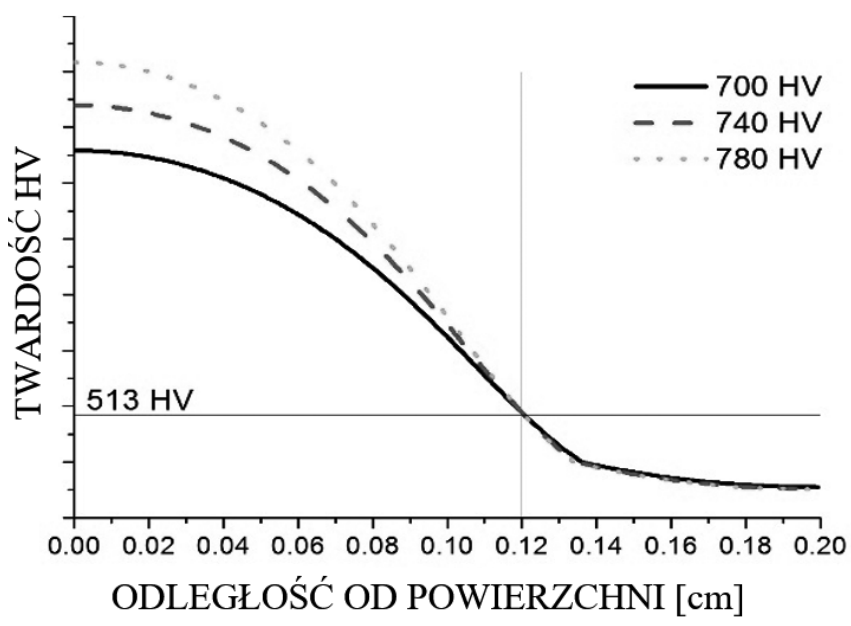

Rys. 1. Model procesu nawęglania

Fig. 1. Model of carburizing process

Wartości twardości trzech warstw, wyznaczone na podstawie symulacji procesu nawęglania, podano w tablicy I, wraz z realnymi wartościami zmierzonymi pod obciążeniem $100 \mathrm{~N}$. Wykonano też profile mikrotwardości HV 0,5 w celu weryfikacji danych modelowych oraz oceny gradientu tego parametru.

Tablica I. Twardość HV10 warstw - modelowa i zmierzona Table I. Hardness HV10 layers - model and measured

\begin{tabular}{|c|c|c|c|}
\hline Wartość modelowa & 700 & 740 & 780 \\
\hline Wartość zmierzona HV 10 & 783 & 797 & 836 \\
\hline
\end{tabular}

Wyniki pomiarów wykonanych na mikro-twardościomierzu Zwick Roel, wskazują, że uzyskane warstwy charakteryzują się wyższą twardości niż założono do celów obróbki powierzchniowej. Dotyczy to wszystkich próbek, jednak zarejestrowane różnice, wynikające ze zmiennego stężenia węgla, są wystarczające do wykorzystania zestawu jako wzorce referencyjne. W dalszych badaniach i opisach wyników posłużono się oznaczeniem twardości uzyskanym w modelowaniu.

Wytworzony zestaw próbek poddano badaniom technikami nieniszczącymi, z zastosowaniem prądów wirowych i analizy szumów Barkhausena. Badania metodą prądów wirowych polegały na ocenie zmian kąta fazowego uzyskanego w efekcie oddalenia od warstw o różnej twardości. Pomiary przeprowadzono z zastosowaniem defektoskopu NORTON 600 firmy OLYMPUS, przy wysokich częstotliwości pola wzbudzającego, na poziomie $5 \mathrm{MHz}$. Skutkuje to ograniczeniem głębokości wnikania prądów w stali ferromagnetycznej do kilkuset mikrometrów, czyli w zakresie grubości warstw hartowanych. Podobne badania, z zastosowaniem prądów wirowych prowadzono także w zakresie oceny stopnia uszkodzenia zmęczeniowego [1,2], stanu składowych naprężenia resztkowych [3], czy też grubości warstw hartowanych [4,5]. Z kolei metoda szumów Barkhausena wykorzystywana była przez autorów $\mathrm{m}$ in. do ilościowej oceny deformacji żelaza Armco [6] oraz stali 13HMF [7], a także do oceny efektów pełzania stali P91 [8].
Po wykonaniu badań metodami nieniszczącymi przeprowadzono badania metalograficzne zgładów przekroi poprzecznych wszystkich trzech próbek. Badania te prowadzono za pomocą mikroskopu metalograficznego NIKON EPIPHOT 200 oraz skaningowego mikroskopu elektronowego SEM Hitachi SU70. Powierzchnie poddane obserwacji mikroskopowej uprzednio przygotowano według standardowych procedur metalograficznych obejmujących szlifowanie, polerowanie i trawienie odczynnikiem Nital 4\% wg PN 61/H-04502. Mikrostrukturę materia-

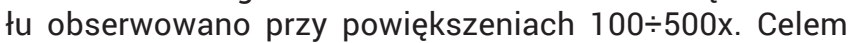
badań było uzyskanie jakościowej charakterystyki mikrostruktury materiału oraz uwidocznienie zmian powodowanych procesem nawęglania.

\section{Wyniki}

Wyniki pomiarów mikrotwardości przedstawione na rysunku 2 potwierdzają rozkład opracowany na podstawie symulacji, czyli fakt uzyskania zestawu próbek o trzech, różnych wartościach twardości warstwy na powierzchni próbek ze stali 6414. Zgodnie z założeniem podwyższona twardość (w stosunku do rdzenia) utrzymuje się do głębokości warstwy (ok. 1,2 mm). Na powierzchni uzyskano różnice ok. $40 \mathrm{HV}$.

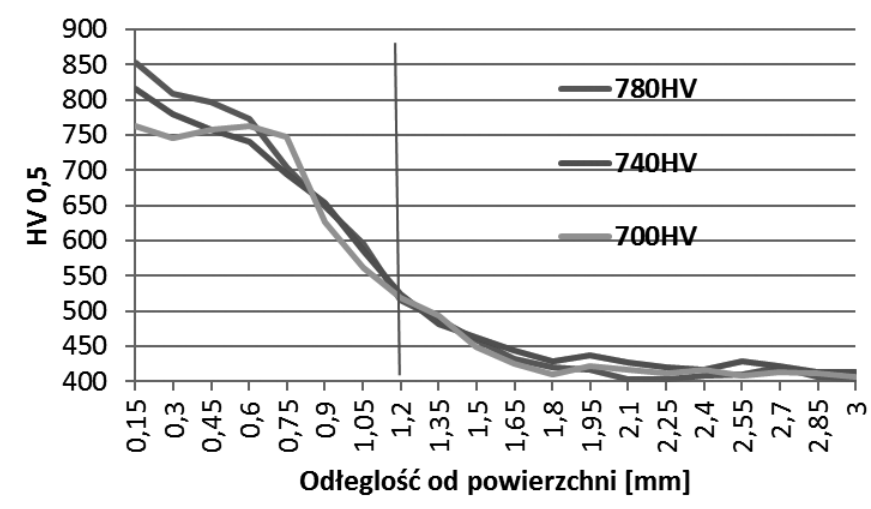

Rys. 2. Profile mikrotwardości

Fig. 2. Micro hardness profiles

Wyniki pomiarów kąta fazowego impedancji uzyskanych w efekcie "lift off" dla trzech próbek z warstwą nawęgloną oraz dla próbki bez warstwy pokazano na rysunku 3.



Rys. 3. Charakterystyka impedancji dla próbek o różnej twardości Fig. 3. Impedance curve for samples having different hardnesses 
Na wykresie są widoczne różnice w wartości kąta fazowego mierzonego sygnału, których wartości dla poszczególnych próbek zestawiono w tablicy II.

Tablica II. Wartości kąta fazowego dla próbek o różnej twardości warstwy nawęglanej

Table II. The values of the phase angle of the samples with different carburized layer hardness

\begin{tabular}{|c|c|c|c|c|}
\hline próbka & bez warstwy & 700 & 740 & 780 \\
\hline kąt fazowy & 12,1 & 19,5 & 27,1 & 31,9 \\
\hline
\end{tabular}

Na rysunku 4 przedstawiono obwiednie sygnału Efektu Barkhausena. Jak widać wzrost twardości (na ogół idący w parze ze wzrostem twardości magnetycznej) skutkuje zauważalnym obniżeniem amplitudy sygnału BE.
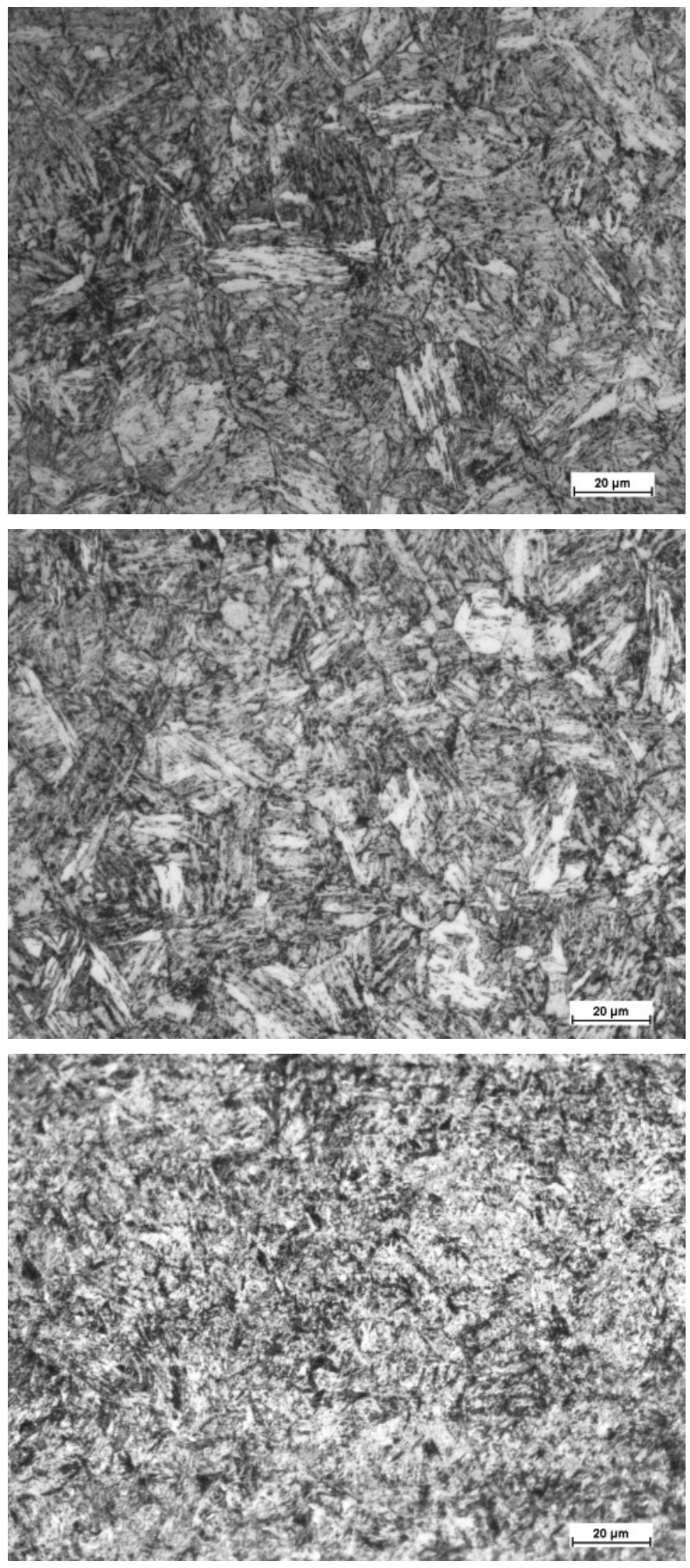

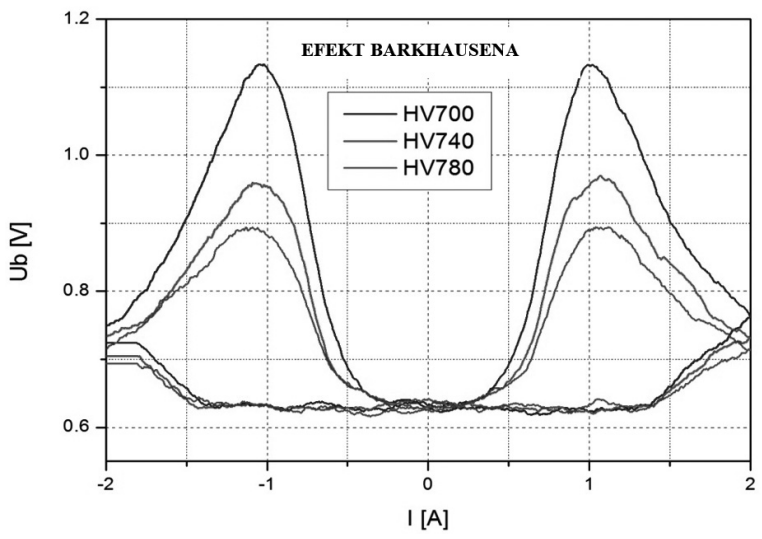

Rys. 4. Charakterystyka zmian sygnału Barkhausena dla warstw o różnej twardości

Fig. 4. Characteristic changes in Barkhausen signal for layers of different hardness
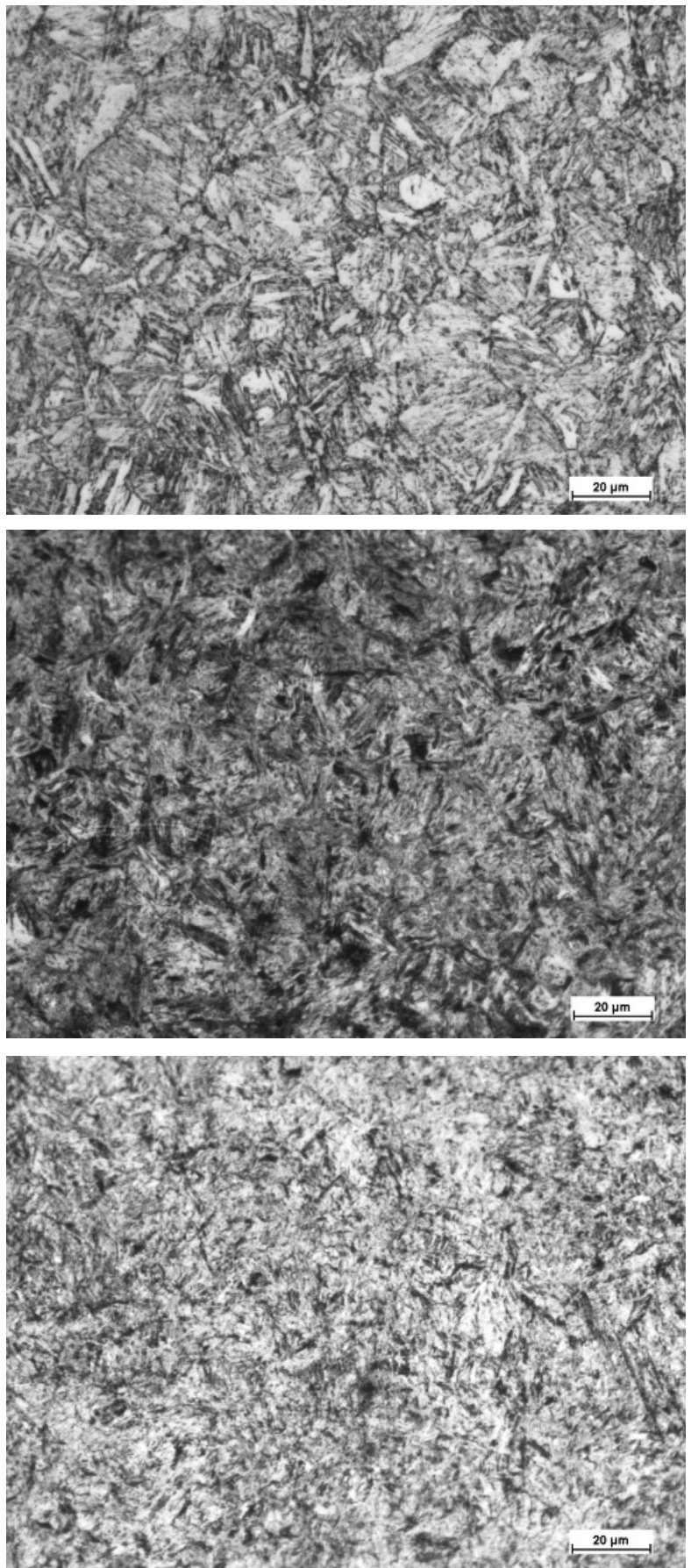

Rys. 5. Mikrostruktury próbek nawęglanych. Zdjęcia wykonane na mikroskopie metalograficznym, pow. 500x

Fig. 5. Carburized microstructure samples. Pictures taken on a metallurgical microscope, 500x magnification 
W przypadku obu metod pomiarowych zarejestrowano wpływ twardości mierzonej warstwy na wartość mierzonego parametru, przy czym różnice w zakresie 700780 HV (a właściwie w zakresie 750-840) są wyraźnie widoczne.

Wyniki badań z zastosowaniem obu technik mikroskopowych przedstawiono w postaci wybranych obrazów mikrostruktur badanych próbek. Na rysunku 5 przedstawiono zdjęcia uzyskane na mikroskopie świetlnym.

Rysunek 6 prezentuje obrazy mikrostruktur rdzenia i warstw uzyskane za pomocą skaningowego mikroskopu elektronowego (SEM).

Na rysunkach 5 i 6 przedstawiono obrazy mikrostruktury rdzenia i warstwy 3 próbek o zróżnicowanej twardości warstwy. Zdjęcia warstw pochodzą z obszaru podpowierzchniowego, gdzie różnice wynikające ze stężenia węgla są najlepiej widoczne. W przypadku rdzenia wszystkie trzy obrazy przedstawiają strukturę martenzytyczną, o podobnej morfologii i wielkości elementów mikrostruktury. W przypadku warstw, widoczne jest coraz większe rozdrobnienie martenzytu wraz ze wzrostem twardości. Wynika to z faktu zwiększenia ilości miejsc zarodkowania martenzytu podczas hartowania wraz ze wzrostem zawartości węgla w warstwie nawęglonej, co w konsekwencji prowadzi do ograniczenia jego rozrostu. Dodatkowo w najtwardszej warstwie można odnotować obecność wydzieleń cementytu.
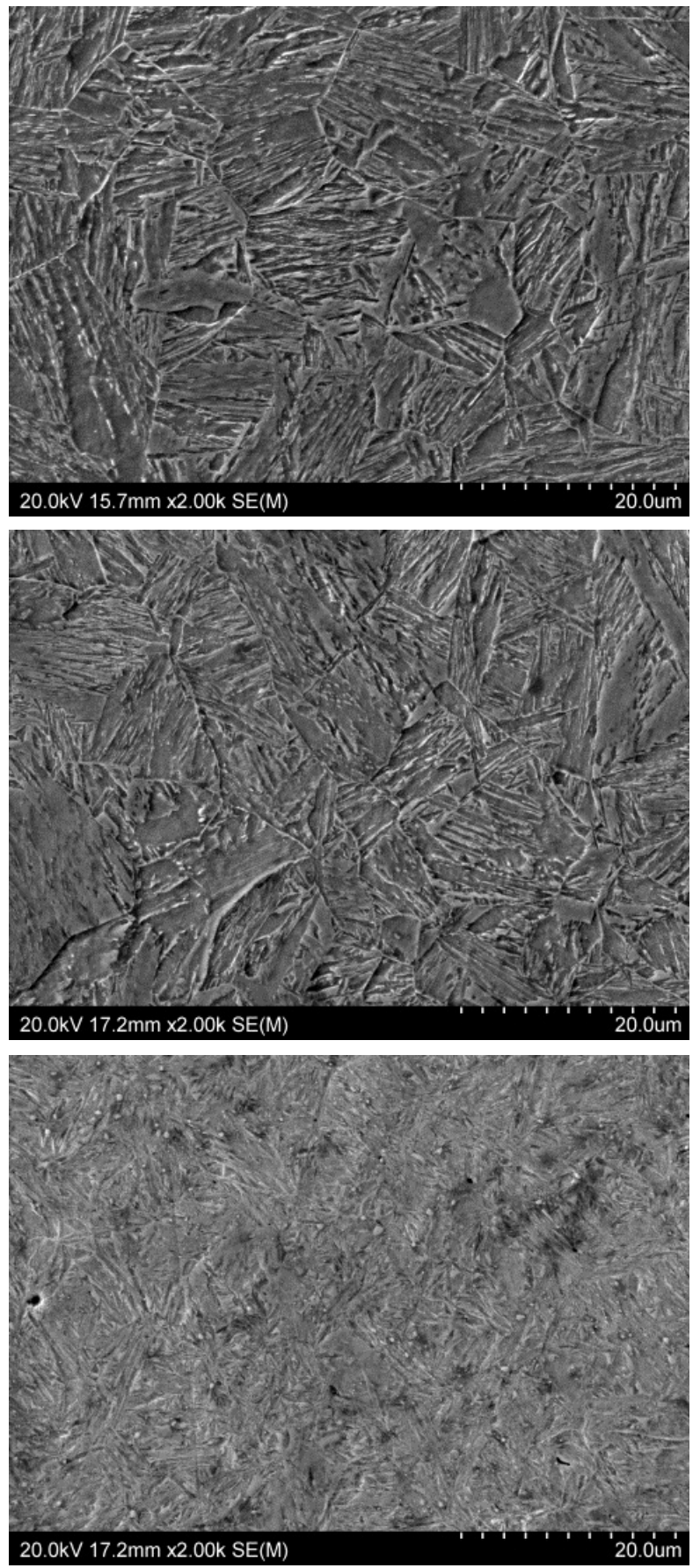
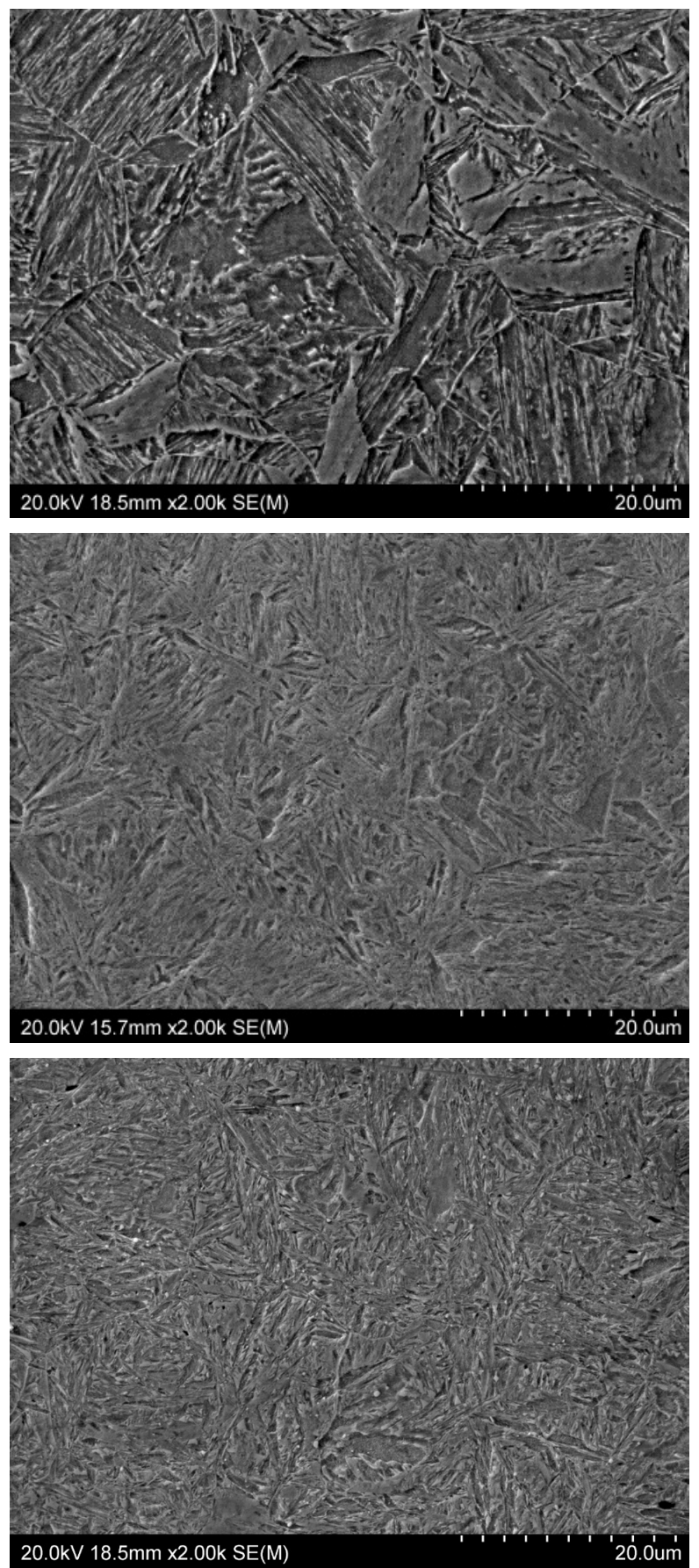

Rys. 6. Mikrostruktury próbek nawęglanych. Zdjęcia wykonane na skaningowym mikroskopie elektronowym (SEM); pow. 2000x Fig. 6. Carburized microstructure samples. Pictures taken on a scanning electron microscope (SEM); 2000x magnification 


\section{Wnioski}

Różnice w twardości warstw nawęglanych i hartowanych indukcyjnie na stali, są możliwe do identyfikacji z zastosowaniem nieniszczących technik diagnostycznych. Przeprowadzone badania potwierdzają skuteczność w tym zakresie $\mathrm{m}$. in. metody prądów wirowych i szumów Barkhausena. Ponieważ jednak metody te są czułe na różne właściwości materiałowe, rejestrowane zmiany mogą być także efektem takich czynników, jak np. zmiany w składzie chemicznym warstwy oraz stan naprężenia w poszczególnych warstwach. Dlatego też wykorzystanie testowanych metod magnetycznych do ilościowej oceny twardości warstw nawęglanych wymaga przygotowania szeregu próbek referencyjnych. Próbki te muszą być dedykowane do konkretnych detali poddawanych kontroli, wykonane z tego samego materiału i według tej samej technologii, z zastosowaniem jednakowych obróbek powierzchniowych.

\section{Podziękowania}

Badania realizowano w ramach projektu finansowanego przez Narodowe Centrum Badań I Rozwoju, nr - 245061.

\section{Literatura}

[1] Krysztofik J., Kukla D., Socha G.: Ocena stopnia uszkodzenia stopu Inconel 718 z zastosowaniem prądów wirowych, Przegląd Spawalnictwa, ISSN: 0033-2364, Vol. 87, No. 12, pp. 36-38, 2015

[2] Kukla D., Zagórski A.: Ocena rozwoju uszkodzenia zmęczeniowego warstwy aluminidkowej na stopie niklu z zastosowaniem technik nieniszczących, Przegląd Spawalnictwa, ISSN: 0033-2364, Vol. 87, No. 12, pp. 18-21, 2015.

[3] Kukla D., Bałkowiec A., Grzywna P.: Evaluation of microstructural changes of S235 steel after rolling on the basis of microscopic observations and eddy current non-destructive method, Advances in Materials Science, ISSN: 1730-2439.

[4] J.M. Szlagowska-Spychalska, M.M. Spychalski, K.J. Kurzydlowski: A novel approach for measuring of thickness of induction hardened layers based on the eddy current method and the finite element modeling, NDT \& E International, Volume 54, March 2013, pp. 56-62.
[5] M.J. Johnson, H. Cao, J.C. Moulder: Eddy-Current and Magnetic Measurements on Case-Hardened Steel, Review of Progress in Quantitative Nondestructive Evaluation, Volume 18 A, pp 1733-1740.

[6] Piotrowski L., Augustyniak B., Chmielewski M., Hristoforou E., Kosmas K.: Evaluation of Barkhausen noise and magnetoacoustic emission signals properties for plastically deformed Armco iron; IEEE Trans. Magn.; vol. 46, no. 2; (2010) pp. 239-242.

[7] Piotrowski L., Augustyniak B., Chmielewski M., Kowalewski Z.: Multiparameter analysis of the Barkhausen noise signal and its application for the assessment of plastic deformation level in 13HMF grade steel; Meas. Sci. Technol. 21, (2010) 115702 (7pp).

[8] Augustyniak B., Chmielewski M., Piotrowski L., Kowalewski Z.: Comparison of properties of magnetoacoustic, emission and mechanical Barkhausen effects for P91 steel after plastic flow and creep; IEEE Transaction on Magnetics; vol. 44. No 11 (2008) p. 3273-3276. 